\title{
Practice Study of Flipped Classroom based on Micro-English Lesson
}

\author{
Lu Wang ${ }^{1, a}$ \\ ${ }^{1}$ Qiqihar Medical University, Qiqihar, Heilongjiang, China, 161006 \\ a email
}

Keywords: Flipped Classroom, Micro-English Lesson, Practice Study

\begin{abstract}
Flipped classroom" is a typical teaching model based on the theory of the formation of blended learning, especially when the United States "flipped classroom" achieved good results in teaching practice, "flipped classroom" quickly became the field of education research hot point. "Flipped classroom" conduct self-learning activities based on micro-lesson video and then cooperative learning, teachers QA activities, so that teachers have more time and energy for students individualized guidance, students also have the greater autonomy and selectivity. This paper studies the problems in traditional English teaching models and points out the practice effect of flipped classroom and we believe this research will be meaningful for the development of flipped classroom.
\end{abstract}

\section{Introduction}

A micro-lesson structure element should contain content elements, identify features, spread elements. Only these three elements are in one place, can it be integrated and matched with each other, in order to use the "flipped classroom". High-quality content is basis of the micro-lesson learning value. Language, text, images, animation, blackboard can meet any efficient expression presentation of a college English knowledge; accurate identification of a micro course includes basic use value, a micro-lesson is a "fragmented knowledge", must be organized and linked through the curriculum, knowledge points, it is important when pass a variety of retrieval tag and retrieving two-dimensional code it belongs.

Rapid spread is the basis for a micro lesson with a good learning experience, micro-lesson video must choose the right format, so as to player normal playback in a variety of environments, the video should be as small as possible, so as to ensure smooth playback speed, must rely on a micro-class platform to access the internet, so that it can support the students learn anytime, anywhere.

\section{Problems in College English Teaching}

College students are mainly from the general high school, vocational technical schools and other secondary school and generally have little interest in learning English, the target is unknown, poor diet, not strong. In a saturation capacity of the classroom, the teacher can maintain the normal teaching order, complete the basic task of teaching is not an easy task and it is almost impossible to take into account the different levels of students' English learning ability. The result is often: a student with high level of English learning ability has not learned enough and poor student cannot learn the English timely.

Teaching activity is that the purpose of college English teaching is to enable students to master certain basic knowledge of English and skills. Simple oral and written communication in daily activities and operational activities of foreign communication and stressed the lay language foundation well and skills-oriented, the principle of sufficient degree.

But taking an overview of curriculum materials, teaching activity which is consistent with this objective is not much. Take Zhejiang Economic and Trade Vocational and Technical College for example, the hospital were used 2 sets of English textbooks, namely a new career Occupation General English (Basic), New Century College English, new Vocational English Reading and Writing, New Practical English comprehensive tutorial (third edition), century practical college 
English, new college English (second edition). Finally, a set of undergraduate teaching, the rest of five sets of high side is too difficult, it applicability needs to be strengthened.

Because the teaching content and assessment methods are limited, combined with a general lack of motivation groups of students, teachers still teach in the actual teaching method. In delivering the information you need to spend more time and the classroom is limited, the content range of workload load the premise of teachers still prefer the traditional teaching methods,

\section{College English Teaching Model based on Micro Flipped Classroom Lesson Practice}

In accordance with the content of training program, teaching requirements, college-level exams and the university English training course is divided into listening and speaking skills, reading skills, writing skills, translation skills training, special training of five modules. It consists of several sub-modules, each module corresponds to a number of objective knowledge and skills objectives, for example, listening and speaking skills training modules include self-introduction and introducing others to seek help in ten minutes module, introduce yourself and introduce others to grasp the corresponding knowledge of the target that is to introduce myself and introduce others the common expression, English skills, goals that is able to introduce ourselves and others (including name, hobbies, occupation, profession, etc.).

Based on the above teaching objectives and the module weight, difficulty, select the appropriate multimedia material, made into a micro-vocational basic English curriculum resource library, including micro video lessons, supplemented by lesson plans, courseware, learning resources and materials. Micro job is supplemented by answering online learning, online testing, online surveys and other independent learning activities feedback. Long control of each video is in 3 minutes and teaching requires are clear objectives and clear sound, quality paintings, in various forms, such as a question and answer, case analysis, etc. Because English is the micro class, with the need to subtitles to help students understand, but because of manpower, time and other restrictions, may be part of resources that can be the winning national college game. We should carry out file self-evaluation, the establishment of independent learning profile. Self-files can be record information of learning English, but also the self-learning process of collecting within the portfolio of the semester student learning objectives, learning experiences and job between each course, test, document revised and team members to discuss the implementation of tasks, topics and other mutual comments made.

In addition, teachers observe and record various aspects of the student's performance, such as the question before class, and other interactive lesson, formative evaluation and summative evaluation, to keep student learning, teaching and learning process and the effect of making appropriate adjustments. Set up a second time and place of classroom activities, students can attend individual lectures, drama performances, English songs, panel debate, all of those will develop the knowledge internalization and expansion of students.

Teachers choose the first western micro lesson contest of College English Practical Writing works as a teaching micro-lesson video and gives students a clear learning objectives, teaching methods, students are required after watching the video in the form of mind maps to complete the learning content induction, specific notification shall include the elements, the main part of the specific information and draw out writing notification. Teachers need to send a job to the mailbox. It makes teachers to communicate with students through the exchange platform and to understand students' feelings and questions.

Given their self-learning, the teachers believe that students have mastered the teaching focus of this course, it directly sets the typical situation course, arranges typical tasks. Teachers observe students' next task execution, timely expand tutoring or collectively explain achieve knowledge construction and internalization. Learning works will give the panel reviewed and teacher comments. 


\section{Research and Practice on Evaluation of "Flipped Classroom"}

Through English-based university "flipped classroom" researching and micro lesson practice, it can be sure that microprocessor-based courses have a positive effect and "flipped classroom" is efficient for the development of college English teaching in theory and practice, but also promote student comprehensive development, enhance respect the professionalism of teachers.

Pad entering the classroom has its unique value, but still active secondary teachers and students, and its value is mainly reflected in:

Make students learning process various, which is pad to enter the classroom core values.

In round monitoring classroom learning process, teachers can observe the students' learning trajectories at which point to watch the micro lesson or other information to complete the correct answer rate practice how and who can carry out exchanges and interaction.

E-learning materials are increasing the type and quantity of learning materials, so that students have the selectivity. "Flipped classroom" in the "first post-teaching, teaching learning-set" is emphasis on the basis of the concept of "Guiding one", teachers are learning designer, organizer, mentor, helper, facilitator. "Flipped classroom" is to promote the implementation of teaching teachers to focus on changing the concept of learning by teaching shift attention to the study of law.

"Life Class" Teaching Mode keeps teaching theory maintaining in research results, introduce information technology to achieve teaching "curricular flip." In learning resources, teacher-student interaction and student-student interaction, learning content and other aspects of the presentation of the original classroom expand the depth and breadth greatly improve classroom teaching.

Application of information technology and learning environment greatly enrich and expand the existing teaching methods, reflects the very good idea of the new curriculum, students can learn at their own pace, teachers can be more "one on one" guidance, and truly reflects the dominant position of students, promote the overall development of students, to be liked and accepted by students and achieves good teaching results;

The "class" is a teaching and learning activities in the presence of "field", "flip" is to change the order of teaching activities, "flipped classroom" has a greater application scenarios that can be adapted to local conditions, a "micro-channel mobile learning", "home flip school "," school flip "," curricular flip "for a creative way to explore the flipped classroom and offers the possibility of localization and more students to provide more effective way;

"Flipped classroom" has the "micro-lesson video", "online training" is a very effective teaching tool that can serve as a useful supplement the existing efficiency of various types of classroom teaching, the introduction of these two elements can enrich existing teaching model, while improving teaching timeliness, promoting the upgrading of student outcomes.

"Flipped classroom" makes teachers a "director", puts forward higher requirements for the teacher's ability. Wherein the production of micro-lesson has a certain degree of difficulty, but also those who need to make a certain amount of exercise can be a good practice to master, but this process is of great significance to promote the professional development of teachers:

It has developed a new way of teaching. Research process is recorded micro-lesson on the nature of an "open class", but this class is completely open without any restrictions by their own master, from design, production to release "train." And through the micro-class platform release, network can be "listening, observation and evaluation," a new way of teaching and research innovation. Follow the author of many of the micro-signal high school chemistry teachers across the country and we often discuss a micro lesson and have a great harvest through Wechat, QQ.

Basic skills of teachers are to enhance lessons micro idea and require accurate transmission of a large number of languages in just a few minutes, text messages. So the ability to express high demands is much meaningful. In 2015, when I just recorded micro class, the middle is always interrupted, a micro-lesson often record several times. Even good record, his time to listen can be found repetitious language, the terminology is not accurate and so on (usually school teachers do not have the other hand, on their own terms). After several years of training, I now have no written record of micro hours after the bullet points to explain the simple idea and one will be able to 
succeed. Everyday in the classroom, it is able to regulate their speed, tone and accuracy of the language. Writing on the tablet, the need is to constantly practice to reach with ease and such exercise to raise the level of teacher writing.

\section{Conclusion}

The Flipped classroom model based on Micro-English lesson is another exploration for the common English teaching theory to breakthrough itself. It helps to resolve many crises for the traditional English classroom under education information age in teaching mode, teaching materials, teaching evaluation and other aspects. The experimental procedure and results are generally accepted by learners, particularly in strengthening interaction and promoting self-learning ability and the learner's subjective perception is on the strongest level. After a comprehensive study, this new model can be implemented in English teaching and must be much meaningful in the near future.

\section{Acknowledgements}

Fund Project: Higher Institute of Heilongjiang Province, the "Thirteenth Five-Year Plan” Higher Education Research Project "Practice Research of Flipped Classroom based on Micro-English Lesson" Project No. $16 \mathrm{G} 288$

\section{References}

[1] Ash, Katie. Educators View "Flipped” Model with a More Critical Eye. Education Week. 2012.

[2] Baker J W. The "Classroom Flip": Using Web course management tools to become the guide by the side. The $11^{\text {th }}$ International Conference on College Teaching and Learning. 2000

[3] McNulty, Ray. Old Flames and New Beacons: The Luminosity of Online Learning. Techniques. 2013.

[4] Berrett, Dan. How "Flipping” the Classroom Can Improve the Traditional Lecture. The Education Digest. 2012.

[5] Fulton, Kathleen. Upside down and inside out: flip your classroom to improve student. Learning. 2012. 